\title{
EnVIRONMENTAl Parasitology. INTERACTIONS BETWEEN PARASITES AND POLLUTANTS IN THE AQUATIC ENVIRONMENT
}

\author{
SURES B.*
}

\section{Summary:}

In recent years there has been an increasing number of papers showing how parasitism and pollution can interact with each other in aquatic organisms. Among the variety of investigated aspects especially the combined effects of pollution and simultaneous infection on the health of aquatic hosts (molluscs, crustaceans, fish, mammals) is of considerable interest. Effects of pollution on the occurrence and distribution of parasites is another interesting field of "Environmental Parasitology" attracting increasing attention. This mini-review presents some promising examples of interdisciplinary studies paying attention to the fact that under natural conditions no organism will only be affected by either parasites or pollution.

KEY WORDS : ecotoxicology, bioindication, biomonitoring, biomarker, fish.

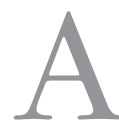
quatic pollution is still a problem in many freshwater and marine environments. It causes negative effects for the health of the respective organisms (Fent, 2007). According to their effects pollutants can either be lethal or sublethal. The effects may manifest immediately (acute toxicity) or after prolonged exposure to the pollutant (chronic toxicity). Although it is not possible to give a detailed picture of all toxic effects the various environmental pollutants might have, the general response of organisms is shown in Figure 1. Organisms such as fish try to avoid the uptake of pollutants by increasing their mucus production. However, this will be effective only in some cases. Usually pollutants are taken up by the gills or the intestine, accumulated until they reach a steady state concentration and then part of the substances will be excreted by the organism. The uptake und accumulation of pollutants is normally also connected with a number of adverse effects which can either be specific (induction of certain proteins, DNA damage, etc.) or more general (changes in hormone levels, effects on the general metabolism).

In addition to pollutants also parasites affect the health of organisms. Part of the responses against pollutants and parasites are similar, whereas also parasite-specific

* Applied Zoology/Hydrobiology, University of Duisburg-Essen, D45117 Essen, Germany.

Tel.: +49(0)201 1832617 - Fax: +49(0)201 1832179.

E-mail: Bernd.Sures@uni-due.de host reactions occur (Fig. 1). Main parasite specific host reactions are defence mechanisms summarized as immune response. But parasite infection is also connected with a general metabolic response as well as with physical damage of the infected organs. The uptake of nutrients and the release of toxic substances by the parasite might cause additional harm to the hosts which can partly be balanced by general activation of the metabolism. Parasites as well as pollutants also affect the endocrine system of organisms. A number of substances alter levels of different hormone groups such as sex hormones (endocrine disrupters, e.g. Fent, 2007) or stress hormones (adrenalin, cortisol or corticosteron, e.g. Wendelaar Bonga, 1997). In parallel also parasites influence sex hormone levels (Hecker \& Karbe, 2005) and stress hormones (Sures et al., 2001).

In addition to effects on free-living organisms pollutants also affect the health of parasites and consequently their occurrence and distribution. In recent years there is increasing awareness that parasitism should be investigated in the light of the respective environmental conditions (e.g. MacKenzie et al., 1995; Lafferty et al., 2004). These studies show that pollution can favour or decrease parasitism depending on an uncountable number of interacting variables.

Therefore, the aim of the present review is (a) to give some examples showing how the combined effects of

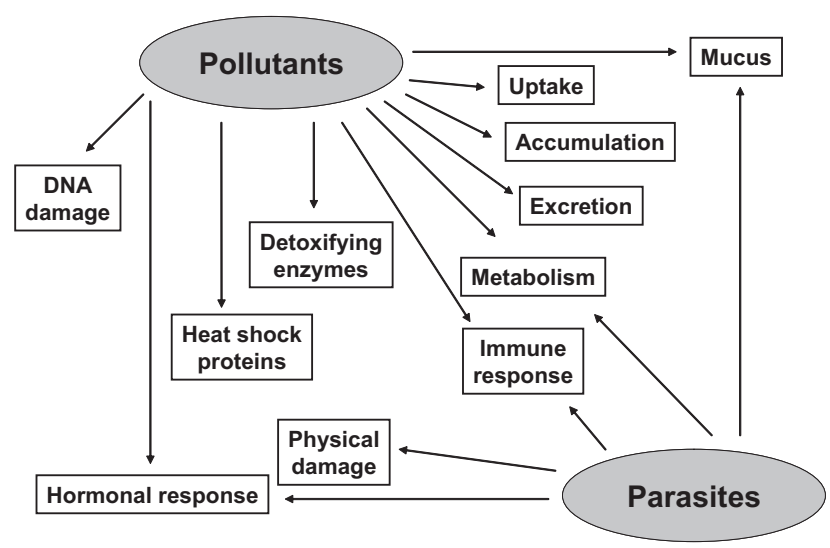

Fig. 1. - Organism's response against isolated pollution or parasitism (modified from Hofer \& Lackner, 1995). 
parasites and pollution interact and how they affect the health of the host; and (b) to present some general trends how pollution affects the occurrence and distribution of parasites.

\section{COMBINED EFFECTS OF POLLUTANTS AND PARASITES}

1 The number of studies investigating effects of pollutants and concurrently occurring parasites is still relatively low (see e.g. Sures, 2006, 2007). This is most likely attributable to the fact that "Environmental Parasitology" is an interdisciplinary field which relies on simultaneous expertise from toxicology, environmental chemistry and parasitology (see e.g. Sanchez-Ramírez et al., 2007). However, the results published so far clearly show that it is worth to combine these expertises. Figure 2 gives an overview of combined effects of parasites and pollution.

For example the accumulation of pollutants by hosts is significantly influenced by certain groups of parasites (Fig. 2). It could be shown in laboratory studies that acanthocephalan infected fish have lower metal levels in their tissues than uninfected conspecifics (Sures \& Siddall, 1999; Sures et al., 2003). Similar results are also available from other host-parasite systems (Evans et al., 2001; Bergey et al., 2002). Following exposure of the freshwater clam Pisidium amnicum to organic pollutants (2,4,5-trichlorphenol and benzo(a)pyrene) mussels infected with larval trematodes contained approximately $12 \%$ less TCP and $40 \%$ less benzo(a)pyrene than the uninfected animals (Heinonen et al., 2000). These reduced pollutant concentration in infected hosts might be beneficial to the infected organisms. In cases when a host faces environmental pollution a parasitosis might be advantageous as infected hosts exhibit lower pollutant levels (and thus less toxic effects) than their uninfected conspecifics. However, this assumption deserves further investigation as it is yet unclear

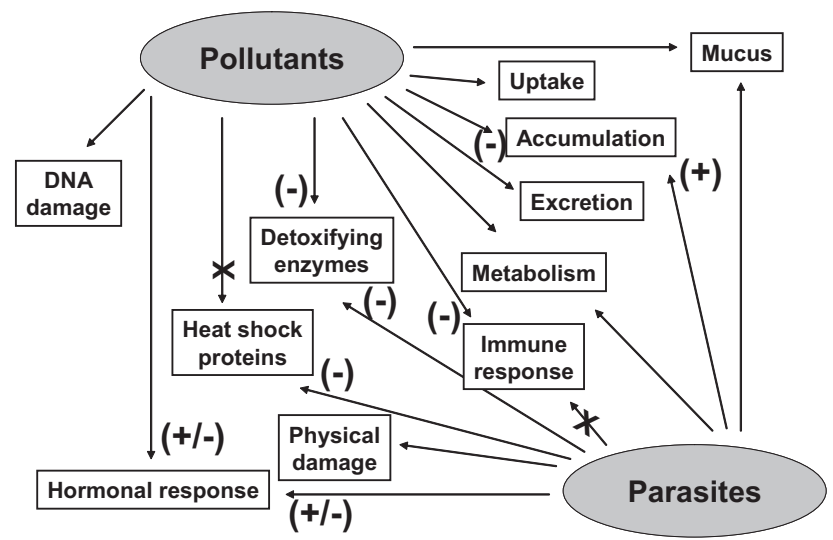

Fig. 2. - Interaction of combined effects of parasites and pollutants. if the negative effects of a parasitosis may be outweighed by the positive impact of reduced pollutant levels.

Not only the accumulation of pollutants is affected by parasites but also some of their effects (Fig. 2). From recent field and experimental studies it emerged that the presence of digenean parasites in Cd-exposed cockles leads to a decrease in metallothionein concentrations compared with uninfected individuals (Baudrimont et al., 2006; Baudrimont \& De Montaudouin, 2007). Similarly, also heat shock responses of infected gammarids can be manipulated by the presence of acanthocephalan larvae within the hemocoel of the crustaceans. Infection of Gammarus roesel $i$ with cystacanths of Polymorphus minutus prevents synthesis of hsp70 in gammarids if they are exposed to the metal palladium (Sures \& Radszuweit, 2007). In both cases infected hosts would suffer more from environmental pollution than uninfected conspecifics as part of their repair and detoxification systems are not working adequately. These negative effects are in clear contrast to the above mentioned beneficial reduction of pollutants in host tissues which makes a trade off even more complicated.

With respect to the endocrine system it is surprising that only a limited number of studies concentrates on combined effects of concurrently occurring parasites and pollutants (see e.g. Klar \& Sures, 2004; Sures et al., 2006) although it is clear that both modify hormonal responses (Wendelaar Bonga, 1997). In a laboratory study, Sures et al. (2006) suggest an antagonistic relation between parasites and pollution. Whereas infection of eels with the swim bladder nematode Anguillicola crassus resulted in increased cortisol concentrations, simultaneously occurring metal and/or PCB pollution reduces plasma cortisol levels. However, from mammalian host-parasite systems contradictory results are documented (e.g. Sures et al., 2002) which makes it impossible at the moment to draw any reliable conclusion on the combined effects of parasites and pollutant on the hormonal homeostasis of the respective hosts.

Comparatively much information is available on the effects pollutants may have on the immune system and thus on host's potential for parasite defence. It is commonly accepted that the immune response of organisms can be impaired due to exposure with immunosuppressive chemicals such as heavy metals and polychlorinated biphenyls (e.g. Arkoosh et al. 1998a, b; Bols et al. 2001). However, most studies dealing with immunotoxicity of xenobiotics are based on challenges with viral and bacterial pathogens or synthetic antigens rather than dealing with parasitic infections (e.g. Regala et al., 2001), which is not surprising since the ability to infect for example fish with a known number of parasites has been achieved only with a few metazoan para- 
site species like Diplostomum sp., Sanguinicola inermis and Anguillicola crassus (Hoole, 1997; Sures \& Knopf, 2004). The general conclusion which can be drawn from the available literature is that immunosuppression by environmental pollutants might be an important factor for the infection success of parasites.

The examples mentioned above show that analyses of the effects of simultaneously occurring parasites and pollutants can be additive, synergistic or antagonistic and that they can not be predicted easily. Until know, those studies analyzing combined effects of parasites and pollutants usually focus on one single marker, such as metal pollution (Sures, 2003, 2004), heat shock proteins (Sures \& Radszuweit, 2007), metallothioneins (Baudrimont et al., 2006; Baudrimont \& De Montaudouin, 2007). For future studies it would be promising to consider all potentially positive and negative effects of parasites and pollutants in a comprehensive approach to answer the question whether it is advantageous to be infected with certain groups of parasites when host populations are confronted with environmental pollution.

\section{EFFECTS OF POLLUTANTS ON PARASITE ABUNDANCE}

I $\mathrm{n}$ recent years there is increasing awareness that parasitism should be investigated in the light of the respective environmental conditions (e.g. MacKenzie et al., 1995; Lafferty et al., 2004). On the first view environmental conditions are mainly important for host's survival and well being. But looking in more detail it becomes clear that host's environmental conditions are also extremely important for parasites although their effects may differ depending on parasite life cycles. For heteroxenous metazoan parasites environmental conditions must be favourable for all host levels (intermediate and final hosts) and for eventually freeliving stages of the parasites. For monoxenous metazoans only the ecological demands of the host and the parasite must be realized. Parasites with direct life cycles are normally ectoparasites. They are in permanent contact with the water and are therefore likely to have developed a resistance to changes in water quality. Consequently, populations of such monoxenous parasites are expected to be less affected by changing environmental conditions compared to heteroxenous parasites (MacKenzie, 1999). A number of studies show that there exists an intimate interaction between environmental conditions and parasitism and that this association is highly vulnerable (e.g. Valtonen et al., 1997; Williams \& MacKenzie, 2003). Apart from the fact that adverse environmental conditions such as water pollution might have deleterious effects on intermediate hosts of heteroxenous parasites and thus reduce parasite abundance, these substances might also have immunosuppressive effects leading to higher infection rates. Accordingly, effects of pollution on parasites may be positive or negative: pollution may increase parasitism, on the other hand it may be fatal for certain parasite species leading to a decrease in parasitism. Generally, infections with ectoparasites tend to increase, whereas infections with endoparasitic helminths tend to decrease with increasing levels of pollution (Sures, 2005).

Differences in the susceptibility of heteroxenous and monoxenous parasites can be used to indicate environmental pollution by calculating the ratio of the sums of heteroxenous and monoxenous $(\mathrm{H} / \mathrm{M})$ parasite individuals per host, as well as the ratio of heteroxenous and monoxenous parasite species richness found on the host fish $\left(\mathrm{S}_{\mathrm{H}} / \mathrm{S}_{\mathrm{M}}\right)$ as suggested by Diamant et al. (1999). The authors found higher H/M ratios and higher $S_{H} / S_{M}$ species richness ratios when comparing parasite communities of rabbitfish (Siganus rivulatus) sampled from an ecologically stable habitat of the Red Sea as compared with the community of fish sampled from anthropogenically impacted environments. Similar results were also described by Perezdel Olmo et al. (2007) when comparing metazoan parasite communities in the bogue (Boops boops), from two localities prior and after the Prestige oil-spill at the Galician coast (Spain). Substantially higher levels of infection with monoxenous parasites, resulting in significantly higher levels of $\mathrm{Sm} / \mathrm{Sh}$ index could be observed in the post-spill samples, clearly indicating a stress response.

The studies presented demonstrate the usefulness of parasites to indicate environmental pollution. The advantage of using numerical changes of parasites to indicate environmental changes such as pollution is mainly that conclusions are not based only on a single species but on a combination of species: host(s) and parasite(s). If a certain parasite is present the ecological demands of all organisms involved in the life cycle must be fulfilled. Therefore, the conclusions drawn from the occurrence of parasites represent an integration of different trophic levels which is not possible using single species approaches for bioindication.

\section{CONCLUSIONS}

E xamples presented within this paper show that the effects of parasites result in varying implications for their hosts not only in parasitological but also ecotoxicological context. Similarly, the examples show that the effects of pollution may be important for parasite survival and establishment. Taken together, it becomes clear that it is important to study 
any effect only under realistic environmental conditions, i.e. effects of pollutants also using infected hosts and parasitological effects on the hosts partly using polluted animals. Under natural conditions no organism will only be affected by either of both. To overcome the deficit of interdisciplinary studies in this field parasitologists and ecotoxicologists should combine their approaches and expertise in order to describe more realistic scenarios organisms are confronted with.

\section{REFERENCES}

Arkoosh M.R., Casillas E., Clemons E., Kagley A.N., Olson R., RenO P. \& STEIN J.E. Effect of pollution on fish diseases: potential impacts on salmonid populations. Journal of Aquatic Animal Health, 1998a, 10, 182-190.

Arkoosh M.R., Casillas E., Huffman P., Clemons E., Evered J., STEIN J.E. \& VARANASI U. Increased susceptibility of juvenile chinook salmon from a contaminated estuary to Vibrio anguillarum. Transactions of the American Fisheries Society, 1998b, 127, 360-374.

Baudrimont M., De Montaudouin X. \& Palvadeau A. Impact of digenean parasite infection on metallothionein synthesis by the cockle (Cerastoderma edule): a multivariate field monitoring. Marine Pollution Bulletin, 2006, 52, 494-502.

Baudrimont M. \& De Montaudouin X. Evidence of an altered protective effect of metallothioneins after cadmium exposure in the digenean parasite-infected cockle (Cerastoderma edule). Parasitology, 2007, 134, 237-245.

Bergey L., Weis J.S. \& WeIs P. Mercury uptake by the estuarine species Palaemonetes pugio and Fundulus beteroclitus compared with their parasites, Probopyrus pandalicola and Eustrongylides sp. Marine Pollution Bulletin, 2002, 44, 1046-1050.

Bols N.C., Brubacher J.L., Ganassin R.C. \& Lee L.E.J. Ecotoxicology and innate immunity in fish. Develop. Comparative Immunology, 2001, 25, 853-873.

Diamant A., Banet A., Paperna I., Westernhagen H.V., Broeg K., KRÜNer G., KÖrTING W. \& Zander S. The use of fish metabolic, pathological and parasitological indices in pollution monitoring. II. The Red Sea and Mediterranean. Helgoland Marine Research, 1999, 53, 195-208.

Evans D.W., IrWin S.W.B. \& FitzPatrick S. The effect of digenean (Platyhelminthes) infections on heavy metal concentrations in Littorina littorea. Journal of the Marine Biological Association of the UK, 2001, 81, 349-350.

FEnT K. Ökotoxikologie. Georg Thieme Verlag, Stuttgart, 2007.

Hecker M. \& Karbe L. Parasitism in fish - an endocrine modulator of ecological relevance? Aquatic Toxicology, 2005, 72, 195-207.

Heinonen J., KukKonen J.V.K. \& Holopainen I.J. Toxicokinetics of 2,4,5-Trichlorophenol and benzo(a)pyrene in the clam Pisidium amnicum: effects of seasonal temperatures and trematode parasites. Archives of Environmental Contamination and Toxicology, 2000, 39, 352-359.
Hofer R. \& Lackner R. Fischtoxikologie - Theorie und Praxis. Fischer Verlag, Jena, 1995.

Hoole D. The effects of pollutants on the immune response of fish: implications for helminth parasites. Parassitologia, 1997, 39, 219-225.

KlaR B. \& Sures B. A nonlinear model of stress hormone levels in rats - The interaction between pollution and parasites. Ecotoxicology and Environmental Safety, 2004, 59, 23-30.

Lafferty K.D., Porter J.W. \& Ford S.E. Are diseases increasing in the ocean? Annual Review of Ecology, Evolution and Systematics, 2004, 35, 31-54.

MacKenzIE K. Parasites as pollution indicators in marine ecosystems: a proposed early warning system. Marine Pollution Bulletin, 1999, 38, 955-959.

MacKenzie K., Williams H.H., Williams B., McVicar A.H. \& SIDDALL R. Parasites as indicators of water quality and the potential use of helminth transmission in marine pollution studies. Advances in Parasitology, 1995, 35, 85-144.

Perez-del Olmo A., Raga J.A., Kostadinova A. \& Fernandez M. Parasite communities in Boops boops (L.) (Sparidae) after the Prestige oil-spill: Detectable alterations. Marine Pollution Bulletin, 2007, 54, 266-276.

Regala R.P., Rice C.D., Schwedler T.E. \& Dorociak I.R. The effects of tributyltin (TBT) and 3,3'4,4'5-pentachlorobiphenyl (PCB-126) mixtures on antibody responses and phagocyte oxidative burst activity in channel catfish, Ictalurus punctatus. Archives of Environmental Contamination and Toxicology, 2001, 40, 386-391.

Sanchez-Ramírez C., Vidal-Martinez V.M., Aguirre-Macedo L., Rodriguez-Canul R.P., Ceja-Moreno V., Gold-Bouchot G. \& Sures B. Cichlidogyrus sclerosus (Monogenea: Ancyrocephalinae) and its host the Nile Tilapia (Oreochromis niloticus) as bioindicators of chemical pollution. Journal of Parasitology, 2007, 93, 1097-1106.

SuRES B. Accumulation of heavy metals by intestinal helminths in fish: an overview and perspective. Parasitology, 2003, 126, S53-S60.

SURES B. Environmental parasitology: relevancy of parasites in monitoring environmental pollution. Trends in Parasitology, 2004, 20, 170-177.

SuRES B. Effects of pollution on parasites, and use of parasites in pollution monitoring, in: Marine Parasitology. Rohe K. (Ed.), CSIRO Publishing, Collingwood, 2005, 421-425.

SuREs B. How parasitism and pollution affect the physiological homeostasis of aquatic hosts. Journal of Helminthology, 2006, 80, 151-157.

Sures B. Host-parasite interactions from an ecotoxicological perspective. Parassitologia, 2007, 49, 173-176.

SuRES B. \& KNOPF K. Individual and combined effects of Cd and 3,3',4,4',5-pentachlorobiphenyl (PCB 126) on the humoral immune response in European eel (Anguilla anguilla) experimentally infected with larvae of Anguillicola crassus (Nematoda). Parasitology, 2004, 128, 445-454.

SuREs B. \& RADSZuweIT H. Pollution induced heat shock protein expression in the amphipod Gammarus roeseli is affected by larvae of Polymorphus minutus (Acanthocephala). Journal of Helminthology, 2007, 81, 191-197. 


\section{SURES B.}

Sures B. \& Siddall R. Pomphorhynchus laevis: the intestinal acanthocephalan as a lead sink for its fish host, chub (Leuciscus cephalus). Experimental Parasitology, 1999, 93, 6672 .

Sures B. Dezfuli B.S. \& Krug H.F. The intestinal parasite Pomphorbynchus laevis (Acanthocephala) interferes with the uptake and accumulation of lead $\left({ }^{210} \mathrm{~Pb}\right)$ in its fish host chub (Leuciscus cephalus). International Journal for Parasitology, 2003, 33, 1617-1622.

Sures B., KNopf K. \& KloAs W. Induction of stress by the swimbladder nematode Anguillicola crassus in European eels, Anguilla anguilla, after repeated experimental infection. Parasitology, 2001, 123, 179-184.

SurEs B., LuTZ I. \& KLOAS W. Effects of infection with Anguillicola crassus and simultaneous exposure with $\mathrm{Cd}$ and 3,3',4,4',5-pentachlorobiphenyl (PCB 126) on the levels of cortisol and glucose in European eel (Anguilla anguilla). Parasitology, 2006, 132, 281-288.

Sures B., Scheef G., Klar B., Kloas W. \& Taraschewski H. Interaction between cadmium exposure and infection with the intestinal parasite Moniliformis moniliformis (Acanthocephala) on the stress hormone levels in rats. Environmental Pollution, 2002, 119, 333-340.

Valtonen E.T., Holmes, J.C. \& KoskivaARa M. Eutrophication, pollution, and fragmentation: effects on parasite communities in roach (Rutilus rutilus) and perch (Perca fluviatilis) in four lakes in central Finland. Canadian Journal of Fisheries and Aquatic Sciences, 1997, 54, 572-585.

Wendelaar Bonga S.E. The stress response in fish. Physiol. Rev., 1997, 77, 591-625.

Williams H.H. \& MacKenzie K. Marine parasites as pollution indicators: an update. Parasitology, 2003, 126, S27-S41. 